\title{
Prerequisites For The Establishment Of Transport And Logistics Centres On The Basis Of Railway Stations
}

\author{
Aikumbekov Muslim', Kamzina Azhar ${ }^{2}$, Arimbekova Perizat ${ }^{3}$, Izbairova Aliya ${ }^{4}$ Altaeva Zhanar ${ }^{5}$, \\ Muratbekova Gulzhan ${ }^{6}$
}

${ }^{1}$ Republic of Kazakhstan, Almaty candidate of technical Sciences, Kazakh Academy of transport and communications named after M. Tynyshpaev e-mail: muslim050182@mail.ru

${ }^{2}$ Republic of Kazakhstan, Almaty candidate of technical Sciences, Kazakh Academy of transport and communications named after M. Tynyshpaev e-mail: azhar0330kad@mail.ru

${ }^{3}$ Republic of Kazakhstan, Almatycandidate of technical Sciences, Kazakh Academy of labor and social relations e-mail: perizat1503@mail.ru

${ }^{4}$ Republic of Kazakhstan, Almaty candidate of technical Sciences, Kazakh Academy of transport and communications named after M. Tynyshpaev e-mail: ialiyas@mail.ru

${ }^{5}$ Republic of Kazakhstan, Almaty candidate of technical Sciences, Kazakh Academy of transport and communications named after M. Tynyshpaev e-mail: zhanar1009@mail.ru

${ }^{6}$ Republic of Kazakhstan, Almatycandidate of technical Sciences, Kazakh Academy of transport and communications named after M. Tynyshpaev e-mail: gv170471@mail.ru

\section{Article History: Received: 11 January 2021; Accepted: 27 February 2021; Published online: 5 April 2021}

\begin{abstract}
Kazakh and foreign economists note that the decline in industrial and agricultural production, stagflation of the economy of the Republic of Kazakhstan in the post-crisis period require a deep analysis of the current situation and careful development of appropriate economic and managerial decisions. In these circumstances, it is necessary to find the most effective ways out of the crisis.It is obvious that it makes no sense for the Republic of Kazakhstan to fully follow the centuries-old path of becoming an industrially developed country. Without a doubt, the modern market economic system should serve as a reference point, which, in addition to free competition, also has numerous internal and external levers of management and regulation, including state ones, which in their essence suppress bursts of fluctuations in the market element and allow using all the advantages and advantages of market relations. One of these ways in the market economy, according to many experts, with whom it is difficult to disagree, is the design of logistics models, the formation, implementation and organization of the rational functioning of logistics services, structures, management systems at the on-farm, industrial (micro logistics) and macroeconomic, international, national, regional (macro logistics) levels, the widespread development and application of logistics methodology, technologies and tools, creation of logistics management systems that differ in their functional purpose and organizational and economic level. When integrating the economy of the Republic of Kazakhstan into the world economic community, there is an increasing need to create reliable, dynamic and efficient domestic logistics management systems that could optimally interact with the national logistics systems of foreign countries in international economic and logistics processes at the macro - and micro logistic levels. These logistics systems are designed to facilitate the rational movement of any flows of information, goods, capital and people both within the country and across the borders of States, taking into account the national peculiarities of customs clearance and support.

Key words: transport and logistics centers, transit transportation, customs procedure, Almaty railway junction, multimodal transportation, logistics and time scheme
\end{abstract}

\section{Introduction}

With the traditional approach to management, each link in the logistics chain has its own management system that focuses on its own goals and performance criteria. The output material flow of each previous link in the logistics chain, formed under the influence of the management system of this link, taking into account its goals and criteria, is the input for the next link. The resulting material flow of the entire logistics chain is the output flow of the last link. Its parameters are determined as a result of independent control actions carried out sequentially in each link of the logistics chain. Therefore, from the point of view of General management purposes, they are random. At the same time, the task of managing the end-to-end material flow is not set and is not solved, since the "end-to-end material flow"category itself is not allocated. As a result, the indicators of this flow (cost, reliability of receipt, quality, etc.) at the exit from the chain, as a rule, are far from optimal.

In the logistics approach, control actions are applied by the unified logistics management system to separate stages of the production and sales process. These control actions are formed based on the General goals and performance criteria of the studied logistics chain in such a way that the output parameters of the end-to-end material flow (point Q) are quite predictable and controlled [1-2].

Kazakhstan is trying to tackle the problems of interaction between transport and the most optimal location of TLCs. In this connection, S. Eliseev justified the possibility of TLC creation on the basis of railway stations. Figure 1 shows the main prerequisites for the creation of a logistics system on the basis of railway stations [3]. 


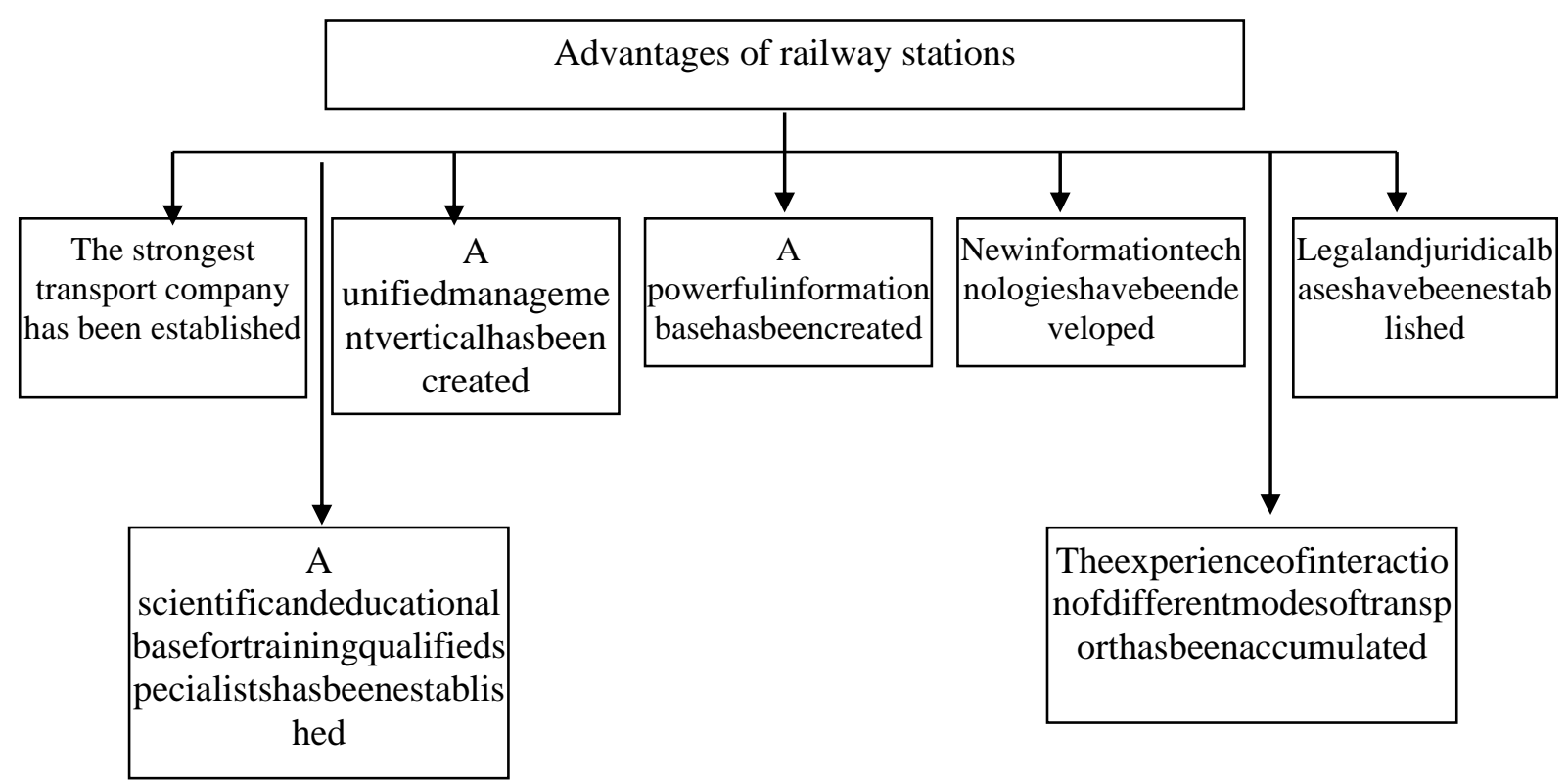

Figure 1 - Main prerequisites for the establishment of transport and logistics centres on the basis of railway stations

Satisfaction of the solvent demand of the population for transport services in accordance with the required quality indicators is one of the important parameters that determine the living standards of the population, which definitely also affects the successful development of the economy. Transport is also one of the most important tools for the harmonization of inter-ethnic and interstate relations, eliminating the trend of differentiation between rich and poor regions, which together ensure political integrity and security of our state.

Creation of TLC on the basis of Aktau port, in spite of rather low rating in the conducted analysis, is conditioned by necessity to develop the functioning of transport and communication complex of the country, which in many respects is determined by development of new types of transport services. These include the dynamically developing national merchant marine fleet. Therefore, at present it is necessary to develop interaction between different modes of transport. Although with the growth of intermodal transport, it is evident that the transhipment of containers from ship to rail and back remains one of the weakest, least efficient and most expensive links in the intermodal transport chain. The quality of railway services provided by the port can be assessed from two points of view: firstly, physical accessibility for the port of the railway system and, secondly, agreements on rates and transport conditions offered by the port in cooperation with a railway company.

Thus, two-level system of TLC location can be applied in Kazakhstan, which, on the one hand, will allow to relieve urban traffic from heavy trucks by creating a network of cargo processing and cargo storage terminals and multimodal terminal complexes of multiple purpose in the zones of large urban agglomerations (Almaty and in the future Nur-Sultan). And on the other hand, the creation of TLCs in the regions in which significant cargo flows of the country are formed or through which they pass, will allow to optimize the work of transport enterprises by improving and developing the production and technical base of the transport complex, the creation and development of modern transport communications and transport and warehouse infrastructure, which ultimately will lead to a rational regulation of regional material and transport flows, optimal routing of transportation, a rational choice of types of transport and storage facilities.

The results obtained through our research on the basis of intersectoral and inter-regional aspects of TLC creation, we believe it appropriate to compare with the planned activities of the Ministry of Industry and Infrastructure Development of the Republic of Kazakhstan on TLC creation within the framework of the plan of transport and logistics services cluster in Kazakhstan. TLC creation is planned on the basis of the following border crossings: Bakhty (East Kazakhstan region), Taskala-Ozinki (West Kazakhstan region), Dostyk, Khorgos (Almaty region), Almaty, Nur-Sultan and Aktau. The analysis of TLCs proposed by the state body allows to conclude that Kazakhstan intends to focus on the realization of transit potential through the construction of TLCs at the border crossings, as well as to improve the conditions for distributors at large freight-consuming points [4].

In accordance with the "Kazakhstan-2050" Strategy, the development of transport infrastructure and 
improvement of the country's transit potential are linked to the establishment of transport and logistics centres to improve the quality of transport services.

ПоэIn order to develop and effectively use the transit potential of the Republic of Kazakhstan, as well as to coordinate the efforts of the state, transport organizations and commodity producers to form effective schemes for promotion of products and services in the markets within the framework of implementation of the transport and logistics cluster, organization at the state level of regional transport and logistics centers in the cities of NurSultan, Almaty, Aktau, as well as at the Dostyk station and other industrially developed regions of Kazakhstan, on the basis of railway stations is being performed. The work of TLC servicing the access roads and stations of the main railway network is carried out according to the unified technological process. In this case, TLCs should carry out the work on regulation of car flows from the access roads and back, regulate the traffic between the individual production facilities [5, 6].

At present, the car turnover of the Almaty hub is 781808 cars per year (2 142 cars per day) (Figures 2, 3, tables 1, 2) [7].

The largest car turnover was reached in 2017 and amounted to 1053382 cars (2 886 cars per day), which was not processed by the Almaty cluster in time and the cars were idle on the way to the hub and waiting for unloading.

At present, the Damu Transport and Logistics Center (hereinafter - TLC) operates at Zhetysu station, which is not fully used.

To relieve Almaty cluster it is proposed to use Damu TLC for cargoes arriving from the north and going to the north direction, for cargo arriving and going to the south direction it is proposed to build TLC at the station Aksengir in the park of passenger cars. It is assumed that 21535 cars per year ( 59 cars per day) will be unloaded at the Aksengir station, 22630 cars per year (62 cars per day) will be loaded, 51100 cars per year will be unloaded at the Zhetysu station (140 cars per day), 1460 cars per year will be loaded (4 cars per day).

To relieve the Almaty hcluster, it is proposed to pass the transit flow along the Kurkuduk-Zhetygen bypass, where it is planned to build _ crossing loop, _ stations, which will be used to pass 239064 cars, which will make up at least 9 pairs of trains per day. It is planned to develop Zhetygen station as a large railway junction, which will be adjacent to the branch from the side of Khorgos, which led to an increase in the size of movement on the Zhetygen - Kurkuduk bypass.

The main cargoes arriving at the Almaty cluster are oil products, construction cargoes, coal and food cargoes, some of which will be distributed to the Damu TLC by the Zhetysu station and at the TLC at the Aksengir station. The certificate of arrival and departure of transit carriages with and without processing to/from Almaty-1 station is presented in tables 1, 2 [7].

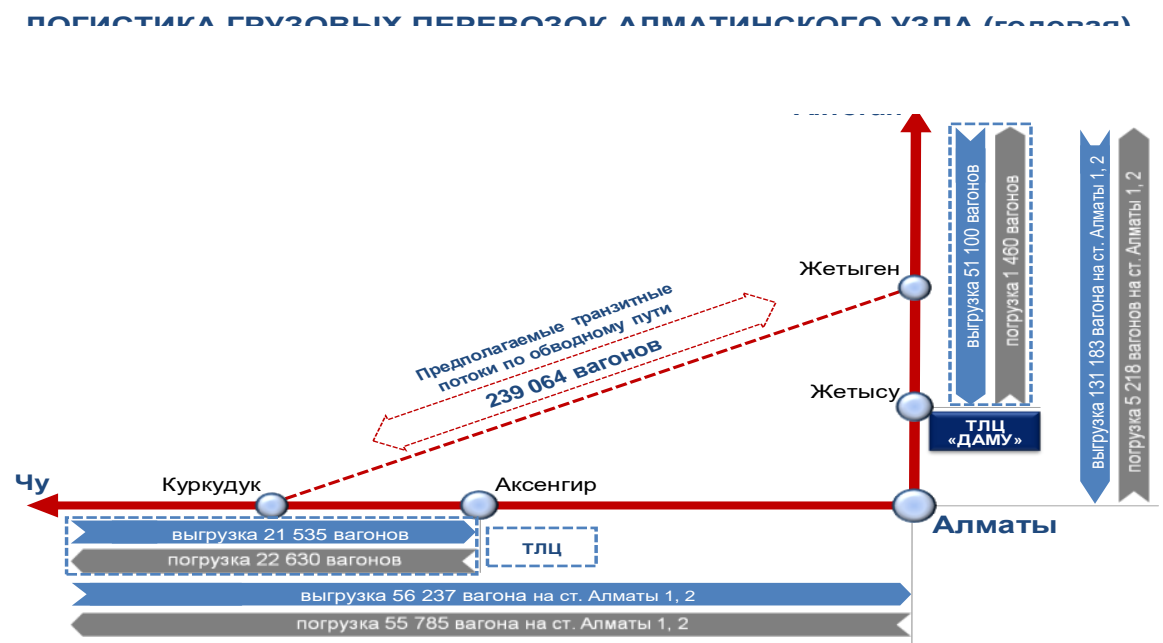

Figure 2 - Cargo Logistics of Almaty Cluster (annual)

Proposed bypass transit flows

239064 cars

$\mathrm{Chu}$

Kurkuduk

Aksengyr 


\section{Zhetysu}

Zhetygen

Aktogay

TLC

Unloading of 21535 cars

Loading of 22630 cars

Unloading of 56237 cars in Almaty 1,2 station

Loading of 55786 cars in Almaty 1,2 station

Almaty

"Damu" TLC

Unloading of 51100 cars

Loading of 1460 cars

Unloading of 131183 cars in Almaty 1,2 station

Loading of 5218 cars in Almaty 1,2 station

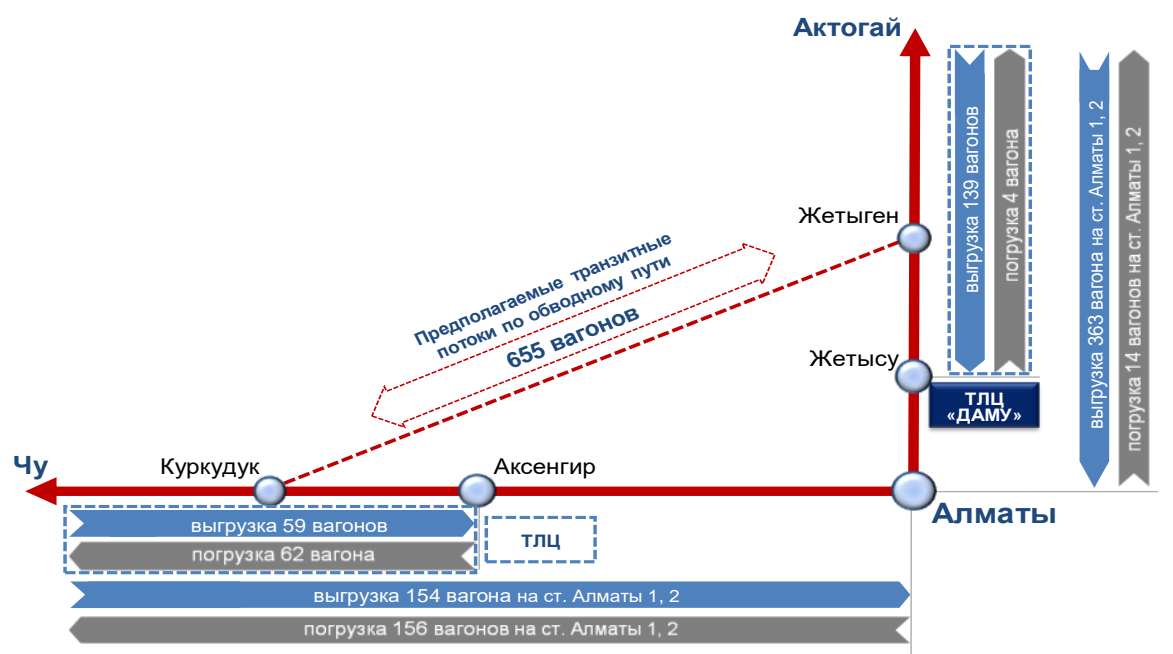

Figure 3 - Logistics of cargo transportation of the Almaty cluster (daily average)

Proposed bypass transit flows

655 cars

Chu

Kurkuduk

Aksengyr

Zhetysu

Zhetygen

Aktogay

TLC

Unloading of 59 cars

Loading of 62 cars

Unloading of 154 cars in Almaty 1,2 station

Loading of 156 cars in Almaty 1,2 station

Almaty

"Damu" TLC

Unloading of 139 cars

Loading of 4 cars 
Unloading of 363 cars in Almaty 1,2 station

Loading of 14 cars in Almaty 1,2 station

Table 1 - South direction

\begin{tabular}{|c|c|c|c|c|}
\hline \multirow{2}{*}{ Year } & \multicolumn{2}{|c|}{ Transit car turnover with recycling } & \multicolumn{2}{c|}{ Transit car turnover without recycling } \\
\cline { 2 - 4 } & arrival & departure & arrival & departure \\
\hline 2015 & 83985 & 73037 & 59914 & 104705 \\
\hline 2016 & 124616 & 124134 & 106434 & 161645 \\
\hline 2017 & 113076 & 114136 & 165715 & 145266 \\
\hline 2018 & 94310 & 95737 & 150291 & 140334 \\
\hline 11 months of 2019 & 65382 & 66400 & 146386 & \\
\hline
\end{tabular}

Table 2 - North direction

\begin{tabular}{|c|c|c|c|c|}
\hline \multirow{2}{*}{ Year } & \multicolumn{2}{|c|}{$\begin{array}{c}\text { Transit car turnover with } \\
\text { recycling }\end{array}$} & arrival & departure \\
\cline { 2 - 4 } & arrival & departure & 26303 & 25827 \\
\hline 2015 & 129577 & 112686 & 70149 & 69010 \\
\hline 2016 & 58532 & 54544 & 73349 & 71548 \\
\hline 2017 & 52499 & 52991 & 68777 & 66477 \\
\hline 2018 & 52171 & 52961 & 56927 & 54574 \\
\hline 11 months of 2019 & 52669 & 53489 & & \\
\hline
\end{tabular}

Among the priority areas of the country, on the territory of which TLCs can be created, the regions bordering with neighboring countries will get new meaning. The only far abroad country bordering Kazakhstan is China. The border with this country passes on East Kazakhstan and Almaty regions [7].

Since transportation of foreign trade cargoes on the territory of East Kazakhstan region is carried out mainly by automobile transport, it is more expedient to create TLC in this region on the basis of automobile passage with China. Therefore, we shall address to TLC which should be created on railway crossing with China, namely, international railway crossing Dostyk-Alashankou. Dostyk station was designed so that the volume of cargo import would be three times higher than export. However, the real freight flows were formed in reverse proportion, which required significant changes in the station's operation technology [8-11].

In accordance with the identified concept of location of transport and logistics centers TLCs at the international crossing Dostyk-Alashankou will have the character of dispersed cargo traffic, its main functions will be aimed at regulating cargo flows to China and countries of South-East Asia. A comprehensive analysis of the routes of transportation between the centers of origin and redemption of goods in Euro-Asian connections shows that the Dostyk station is advantageously located in the area of the junction of routes in the south-eastern direction with the countries of Southeast Asia.

Thus, the creation of TLC at Dostyk will allow to organize the work of the station with a more rhythmic and timely supply of goods going in the direction of China.

Analyzing the activity of the international railway crossing Dostyk, it is possible to distinguish a number of problems that arise during transportation of cargoes through this station, similar to the problems that arise during transportation of cargoes during interaction of railway and sea transport in the Russian Federation, which are reflected in Table 3.

Firstly, the existing planning system at railway transport has remained rigidly centralized and therefore not flexible. Any deviations in the process of plan execution lead to failures of the transport multimodal conveyor. The reasons for such disruptions may be the economic situation in the country and in the world, including changes in the demand and prices on the world market for certain cargoes, which leads to an increase or decrease in loading in certain periods of the year, changes in customs policy in our country and countries-importers of domestic products through changes in customs duties, which leads to an increase or decrease in exports of goods in certain periods of time.

Such reasons for railway transport include unscheduled loading of cargoes, supply of cargoes to the junction stations of the crossings earlier or later than planned, uneven loading within a month (decade). 
Secondly, there is no authority that can promptly and efficiently adjust cargo flows, redistributing them depending on the load of transshipment sites at the junction stations.

Table 3 - Main problems arising during transportation of cargoes in export-import operations

\begin{tabular}{|l|l|}
\hline Strictly centralized planning system at railway transport \\
\hline $\begin{array}{c}\text { Absence of a body capable of promptly and efficiently adjusting cargo flows, redistributing them } \\
\text { depending on the load of transshipment sites at the junction stations }\end{array}$ \\
\hline $\begin{array}{c}\text { Accumulation of cars in the station region due to unaccounted supply of cars to the junction stations } \\
\text { by independent carriers }\end{array}$ \\
\hline $\begin{array}{c}\text { Early delivery leads to a build-up of cars on the entrances to the junction stations, which makes it } \\
\text { difficult to maneuver and train, and turns cars into warehouses on wheels. }\end{array}$ \\
\hline
\end{tabular}

Thirdly, a group of independent carriers, which do not yet participate in this planning scheme, has emerged and tends to develop actively. The implementation of the agreed delivery of cargo flows without taking into account the delivery of cars to the docking stations by independent carriers will inevitably lead to the accumulation of cars in the station region.

Fourthly, according to the Civil Code of the Republic of Kazakhstan, the carrier is responsible for late delivery of cargo only in case of exceeding its term, but does not guarantee delivery on time. Early delivery of the cargo leads to the accumulation of cars on the entrances to the junction stations, which complicates maneuver and train work, and also turns cars into warehouses on wheels.

All the above mentioned problems require the creation of a logistics center, which should manage cargo flows, link the technical capabilities of the railway, ensure efficient transshipment of cargoes at the junction stations without long downtime of cars on the entrances to them waiting for unloading, represent the interests of all modes of transport involved in multimodal transportation, and take into account the interests of cargo owners.

The main task of TLC at this station will be to regulate the planning of cargo flows taking into account the processing capacity of the station. Principal scheme of TLC operation at Dostyk station is shown in Figure 4.

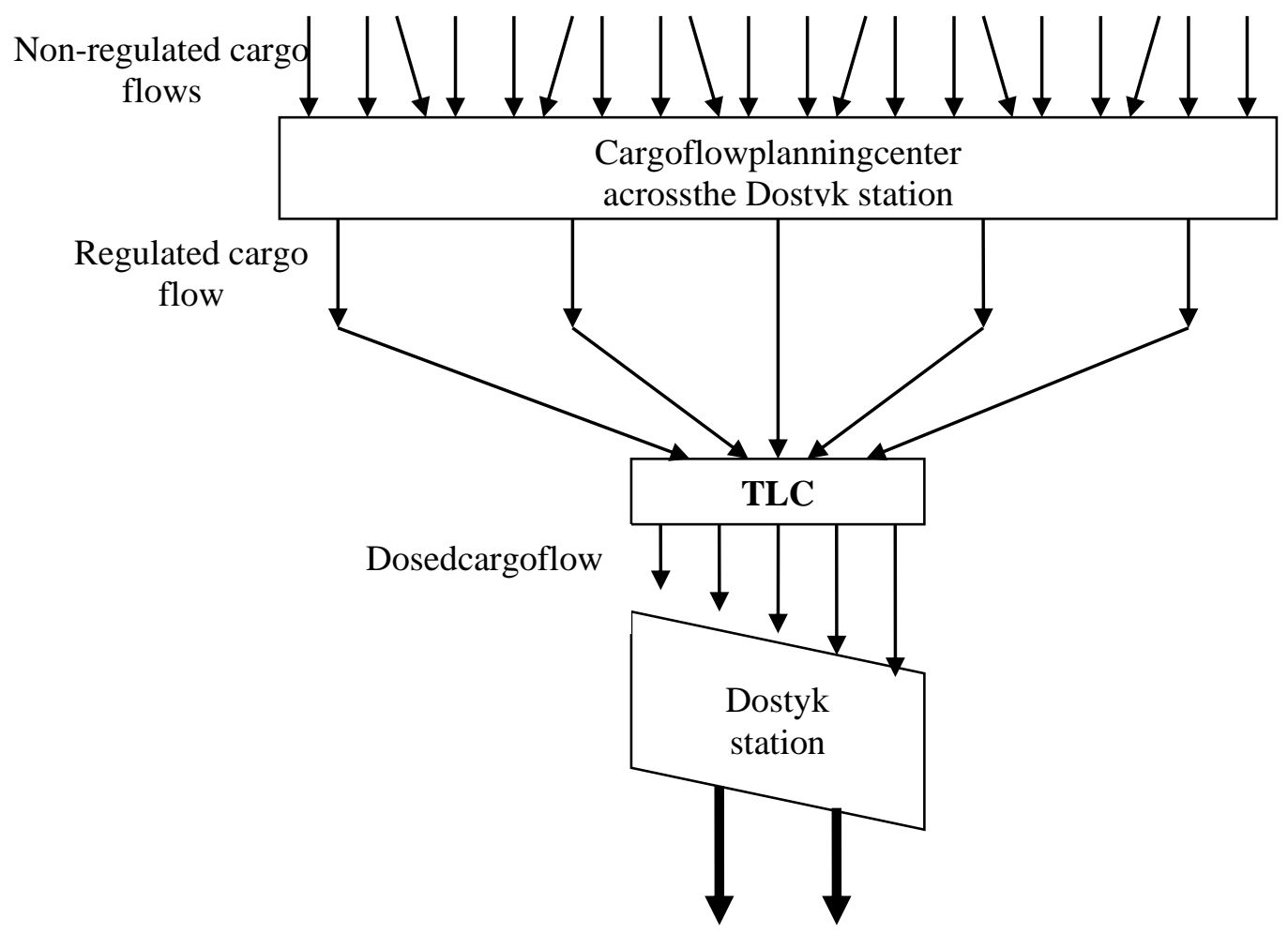

Alashankousss 
Figure 4 - Principal scheme of regulation of car flows from Kazakhstan to China with participation of TLCs

A characteristic feature of the planned TLC at Dostyk station will be a geographically distributed method of cargo delivery, which will include all the nearby stations, which will form the flow of goods in accordance with the requirements of the TLC. The so-called first order support stations (Aktogay station) and second order support stations (Semipalatinsk, Moyynty and Almaty stations) should be distinguished here. Figure 5 shows the scheme of TLC operation at Dostyk station and its interconnection with first- and second-order stations.

Territorially, the work of TLC of Dostyk station is a system that includes not only the transport cluster of the transition, but also adjacent stations, which according to the developed plan of formation of trains will coordinate the flow of freight cars to organize the rhythmic work of the transition. The main task of TLC is organization of rhythmic work of the station for processing of approaching cargoes in three directions: Eastern, Central and Southern Kazakhstan, taking into account the available processing capacity of the transshipment sites [8-11].

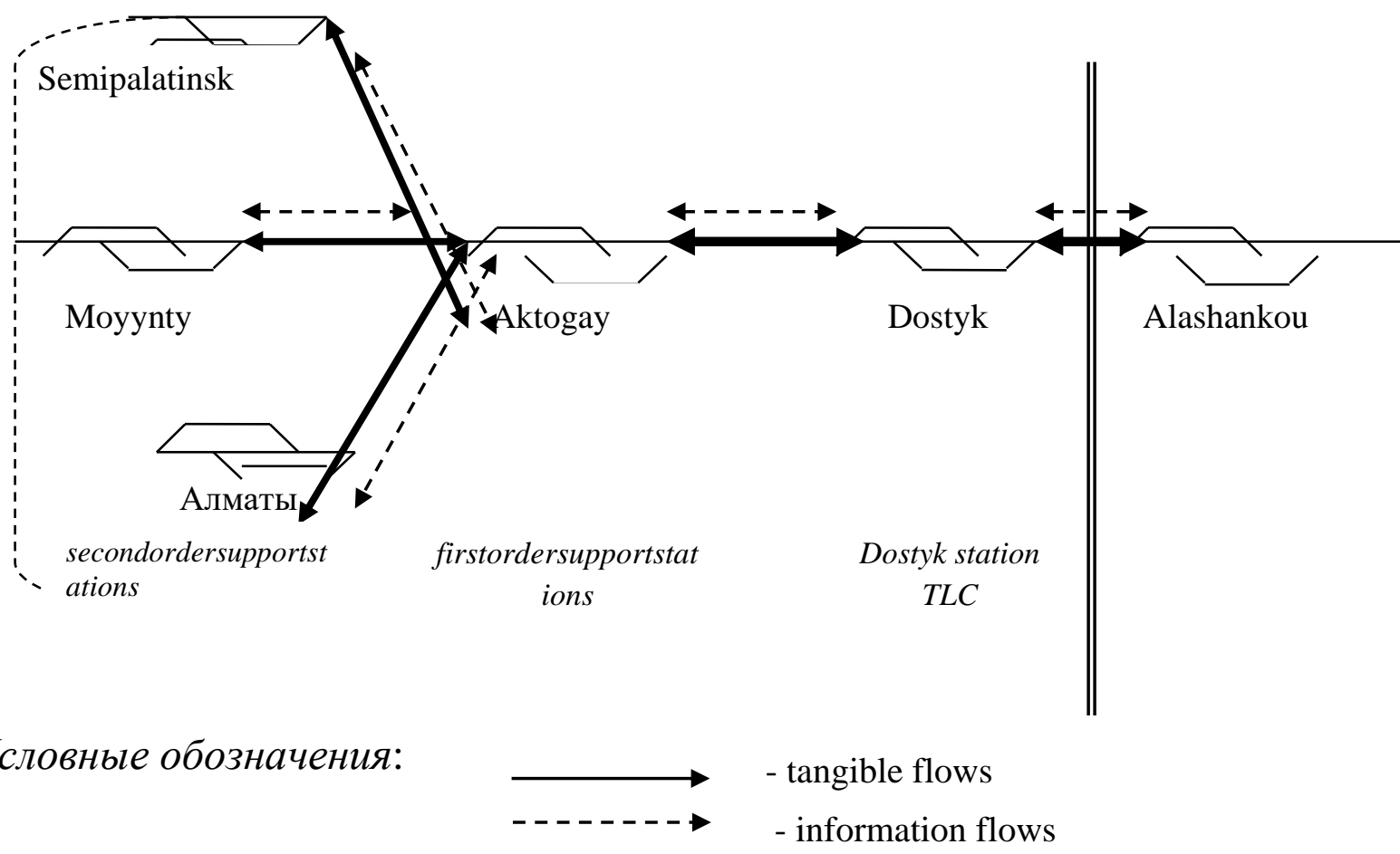

In order to improve the work of the international railway crossing Dostyk-Alashankou, Professor N. Isingarin has developed a logistic-temporal scheme (LTS), which involves coordination of actions of all participants of the transport and distribution process in time, space and by types of cargoes of all material and associated flows, consistently passing through all stages of storage, transportation, transshipment, warehousing, cargo processing and delivery of goods to direct consumers.

Based on the logistic-temporal scheme, Figure 7 N. Isingarin proposed an organizational scheme of the transport process participants work within the regional logistics system. 


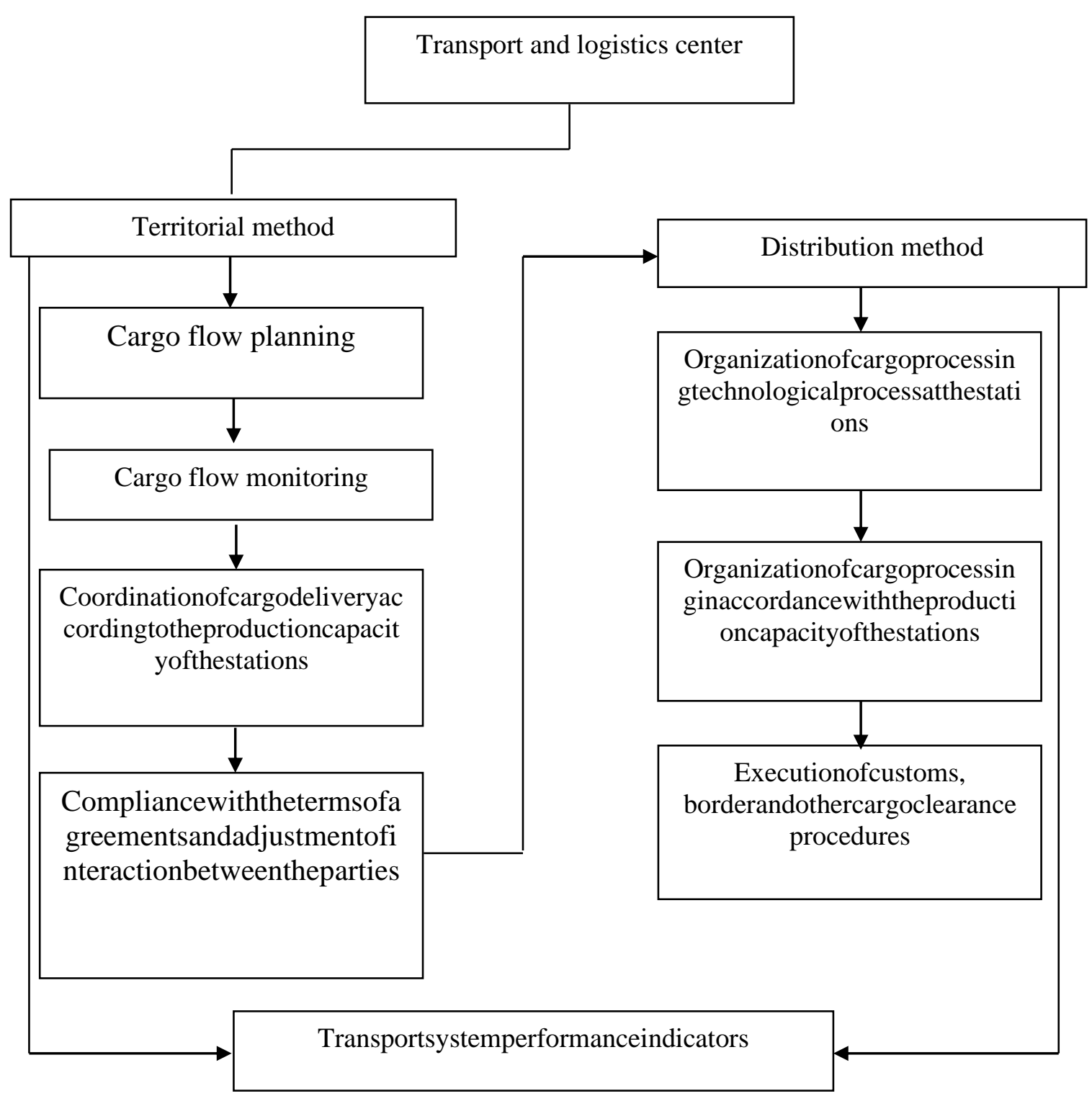

Figure 7 - Organizational chart of TLC functioning

The main purpose of the proposed organizational scheme of TLC activity is to build the transition station operation in such a way as to minimize the time required for cargo delivery to the station, its processing and execution of relevant documents based on the main provision of the transport process continuity.

This scheme defines the main tasks of TLC for the rhythmic operation of the station during the transportation of goods. The system approach according to which the purpose of the lower level is a means of achieving a higher purpose allowed to consider the station activity in a complex way.

Planning of cargo traffic, the organization of processing facilities of the station, cargo clearance procedures and the agreement of the receiving party identified as the main activities of TLCs represent a comprehensive program of TLC activities, taking into account all aspects of the activities necessary for the rhythmic transportation of goods.

In accordance with the assigned task on cargo flow planning it is necessary to monitor cargo flows at the level of tactical actions for timely preparation of the appropriate processing place at the plant. For this purpose, it is necessary to have an information-analytical center at the TLC for processing and storage of large amounts of information about the terms and volumes of approaching trains from the first and second order support stations. If necessary, it will be possible to quickly coordinate the cargo flows in the direction of the TLC, which implies either an accelerated approach or some delay of the train based on the actual load of the processing sites. Coordination of the station's activity in terms of the cargo processing technological process will be concluded for the TLC in the direction of cargoes in accordance with the purpose of the processing place at the station, taking 
into account their production capacity and purpose of cargoes: for export/transit or for domestic use, as well as in accordance with the storage period of cargoes. Taking into account the fact that the participants of the cluster system in the transport complex are also executive authorities, in particular customs, border and other authorities interested in the rhythmic work of the station, we have also included the implementation of the prescribed cargo clearance measures among the tasks of the TLC. Timely execution of documents for the transported cargoes will allow avoiding their delay and, accordingly, not interrupting the rhythmic process of processing cargo flows through the crossing station.

The process of agreement of volumes and technology of TLC operation with the receiving parties, which is allocated in a separate strategic task, also helps to organize rhythmical and timely work of the station. Predetermined types and volumes of cargoes to be transferred to the receiving party in accordance with the annual plan of their reception will allow shippers to orientate in their ability to provide the planned cargoes for reception in time.

The scheme of TLC operation in accordance with the listed tasks shall be strictly time regulated operations for each individual function at the transition station. The block of performance indicators of the implemented tasks provided for in the scheme will allow us to evaluate the actually obtained performance indicators with the planned ones, which, if necessary, can be adjusted. In general, the proposed activities in the scheme of activities of the regional transport system with the participation of TLC should be based on scientifically developed standards, norms and rules of quality of freight transportation.

Thus, complex, interconnected, holistic consideration of various aspects and sides of formation, functioning and improvement of complex logistic systems on the basis of the system approach taking into account comparison of activity indicators with the set goals will allow to solve questions of coordination of many links of the regional transport system within the framework of transport and logistic centers.

All the mentioned above testifies to the fact that functioning on the TLC market should come to the conclusion that their activity should tend to merge or split into types of activity and the maximum possible information interaction to increase mutual efficiency [8-11].

\section{Conclusion}

Among the services of forwarding companies, the most popular are local transportation (100\%) and international transportation (67\%). Tracking and promotion of cargo along the entire route and searching for wagons is relevant $(8 \%)$. Other services are left without attention on the part of shippers, which indicates the complexity of the services provided by local freight forwarders. Note that local TLC with rare exceptions provide all services (this is the preference of shippers).

The analysis of cargo flows in export-import and transit traffic shows an increasing rate of mineral exports. The share of bulk cargo originating and absorbed in places of non-public use (on the territory of enterprises, organizations, associations, etc. that have railway access roads) in the total volume of cargo transportation by rail was $93 \%$.

It is necessary to use the TLC as a center serving access roads that are technologically connected to the overall production process of the enterprise. The work of the TLC that serves access roads and stations of the main railway network is carried out according to a single technological process. In this case, the TLC must perform the work of regulating the car traffic coming from the access roads and back, regulate the movement between individual production facilities.

\section{References}

1. Gerami V. Management of transport systems. Transport logistics support. Textbook. - Moscow: YURAYT, 2016. - $440 \mathrm{p}$.

2. Lukinskiy V. Logistics and supply chain management. Textbook. - Moscow: YURAYT, 2016. - 360 p.

3. Eliseev S. The concept of freight transport management in transport hubs with the use of logistics centers //Report at the scientific and practical seminar "Development of logistics of transit cargo transportation in international communications", Moscow, 2005.

4. Research project program 010 "Applied scientific research in the field of transport and communications" of the Ministry of transport and communications of RK's project on "study of the conditions of functioning of transport-logistic centers, development of mechanisms to encourage their establishment in Kazakhstan and research-based recommendations for their development". Astana, 2017 and 2018. 
5. Djanisenova A. Transit and transport potential of the Republic of Kazakhstan: the state and prospects of forming cargo flows. // Bulletin of the National Academy of Sciences of the Republic of Kazakhstan, Almaty, 2008, Issue 6, Pp. 71-75

6. Muhametjanova A. Conditions and directions of development of multimodal transport. // Industrial transport of Kazakhstan. - Almaty, 2008. - Issue 4

7. Report on the work of the Almaty branch-Cargo transportation JSC for 2015-2019.

8. Isingarin N. Energy and transport in a single corridor //Kazakhstanskaya Pravda. - Almaty, 2008. No. 22.

9. Prosvetov G. Mathematical methods in logistics. Problems and solutions, Moscow: Alfa-press, 2017, 304 p.

10. Logistics: integration and optimization of logistics business processes for delivery purposes / V. Dybskaya. - Moscow: Eksmo, 2014. - 939 p.

11. Sarkisov S. Logistics and transport deprivation VJD: Textbook. - M .: VAVT, 2015. - 216 p. 